\section{THE AMERICAN JOURNAL OF}

\section{PSYCHIATRY}

\section{Contents}

\section{April 2014, Volume 171}

\section{Editorials}

381 Marijuana and adolescence: what can we learn from primates?

Cheryl Corcoran

384 Treatment of depression: men and women are different? Myrna M. Weissman

388 Computerization of the therapeutic task of working through

Robert Freedman

391 Toward personalized medicine in the pharmacotherapy of alcohol use disorder: targeting patient genes and patient goals

Steven L. Batki and David L. Pennington

\section{Commentary}

395 The NIMH Research Domain Criteria (RDOC) project: precision medicine for psychiatry

Thomas R. insel

\section{Clinical case conference}

398 Management of clozapine-induced fever in a child David I. Driver, Afsoon A. Anvari, Christina M. Peroutka, Rachna Kataria, Jerry Overman, David Lang, Maria Tietcheu, Reggie Parker, Keith Baptiste, Judith L. Rapoport, and Nitin Gogtay

\section{Images in psychiatry}

403 Johann Christian Reil (1759-1813): pioneer of psychiatry city physician, and advocate of public medical care Maximilian Schochow and Florian Steger

\section{Reviews and overviews}

404 Antidepressant-induced liver injury: a review for clinicians cosmin Sebastian voican, Emmanuelle Corruble, Sylvie Naveau, and Gabriel Perlemuter

\section{New research - articles}

416 Repeated $\Delta^{9}$-tetrahydrocannabinol exposure in adolescent monkeys: persistent effects selective for spatial working memory

Christopher D. Verrico, Hong Gu, Melanie L. Peterson, Allan R. Sampson, and David A. Lewis

426 Sex differences in the pathways to major depression: a study of opposite-sex twin pairs Kenneth S. Kendler and Charles 0 . Gardner

436 Computer-assisted delivery of cognitive-behavioral therapy: efficacy and durability of CBT4CBT among cocaine-dependent individuals maintained on methadone Kathleen M. Carroll, Brian D. Kiluk, Charla Nich, Melissa A. Gordon, Galina A. Portnoy, Daniel R. Marino, and Samuel A. Ball

445 Topiramate treatment for heavy drinkers: moderation by a GRIK1 polymorphism Henry R. Kranzler, Jonathan Covault, Richard Feinn, Stephen Armeli, Howard Tennen, Albert J. Arias, Joel Gelernter Timothy Pond, Cheryl Oncken, and Kyle M. Kampman

453 Comprehensive meta-analysis of excess mortality in depression in the general community versus patients with specific illnesses

Pim Cuijpers, Nicole Vogelzangs, Jos Twisk, Annet Kleiboer, Juan $\mathrm{Li}$, and Brenda W. Penninx

463 Head injury as risk factor for psychiatric disorders: a nationwide register-based follow-up study of 113,906 persons with head injury Sonja Orlovska, Michael Skaarup Pedersen, Michael Eriksen Benros, Preben Bo Mortensen, Esben Agerbo, and Merete Nordentoft 